\title{
A Study of the Risk Factors Predicting Amputation in Diabetic Foot
}

\author{
Amara Simha Reddy. $\mathbf{T}^{\mathbf{1}}$, Prashant G.K. ${ }^{2}$ \\ ${ }^{1,2}$ Assistant Professor, Department of General Surgery, Chalmeda Anand Rao Institute of Medical Sciences, \\ Karimnagar.
}

Corresponding Author: Prashant G.K.

\begin{abstract}
Background: Diabetic foot ulcers are the main cause of non-traumatic lower extremity amputation. The objective of this study was to evaluate the risk factors for major amputation in diabetic foot patients.
\end{abstract}

Materials \& Methods: This open, single center, prospective and observational study conducted in Chalmeda Anand Rao Institute of Medical Science, Karimnagar for a period from Nov. 2018 to Dec. 2020 The patients admitted in General Surgery with diabetic foot problems were selected for the study with proper consent of patients and his/her attendants.

Results: In this study fifty patients were admitted to the diabetic wound in Department of Surgery for foot ulcers between Nov 2018 to Dec 2020. Among the 50 patients, Male: Female ratio was 4.6:1. Out of which $41(82.0 \%)$ were male, $18(36.0 \%)$ belonged to the 50 to 59 years age group, $15(30.0 \%)$ were having complaints for Ulcer, $15(30.0 \%)$ were smoker. The Amputation rate was $42.0 \%$.

Conclusion: In the results of analysis, poor glycemic control, peripheral arterial disease, peripheral neuropathy and higher Wagner grade are significant risk factors for amputation in diabetic foot infection.

Keywords: Diabetic foot, Wagner grading, HbA1c, TLC, Albumin

\section{INTRODUCTION}

According to the World Health Organisation and to the International Working group on the Diabetic foot, diabetic foot is defined as infection, ulceration or destruction of tissues of the foot associated with neuropathy and/or peripheral artery disease in the lower extremity of the people with diabetes ${ }^{(1)}$.

The prevalence of diabetes is rapidly rising all over the globe at an alarming rate (2). As per WHO, 422 million adults aged over 18 years were living with diabetes in

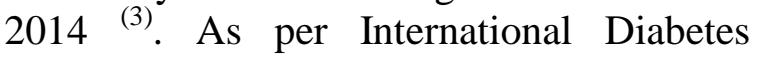
Federation (IDF) Diabetes Atlas, 424.9 million people worldwide, or $8.8 \%$ of adults 20-79 years, are estimated to have diabetes by the end of 2017 and 629 million people between 20-79 years will have diabetes by the end of $2045^{(4)}$.

As per IDF Diabetes Atlas, India is home to the second largest number of adults living with diabetes worldwide after China with 72.9 million people between 20-79 years by 2017 and if the same trend continues India will become Diabetic capital of the world with 134.3 million people with diabetes by $2045^{(4)}$.

The reported prevalence of diabetic peripheral neuropathy ranges from $16 \%$ to as high as $66 \%$. Amputation in diabetics is 10-20 times more common as compared to those of non-diabetics. Every 30 seconds a lower limb or part of a lower limb is lost to amputation somewhere in the world as a consequence of diabetes ${ }^{(4)}$. The aim of this study is to identify the predictive factors for major lower limb amputations among patients with diabetes mellitus who get admitted to our hospital for diabetic foot problems.

\section{Objectives:}

The effects of Duration of Diabetes mellitus, low serum albumin levels and a 
positive bacterial culture on being predictors of patients undergoing major lower limb amputation.

\section{MATERIALS AND METHODS}

This open, single centre, prospective and observational study to be conducted in Chalmeda Anand Rao Institute of Medical Science, Karimnagar for a period from Nov 2018 to Dec 2020 The patients admitted in General Surgery with diabetic foot problems will be selected for the study with proper consent of patients and his/her attendants.

The inclusion criteria were patients who are diagnosed cases of diabetes for more than 10 years, above 30 years of age and of either gender. Patients were excluded with the history of limb trauma. Formal written informed consent was obtained from all the patients. The study was approved by the institutional ethical committee.

Data of patients was collected in the form of presenting complaints, history of present condition, clinical history, general physical, systematic and local examination, relevant risk factor identification and laboratory evaluation. Data was collected in a per test pro forma which includes the details like: age, sex, occupation, subjective complaints(S), objective findings (O), assessment of clinical condition (A) and plan of management. The analysis of collected data will be made with appropriate statistical parameters.

\section{Statistical Analysis:}

Continuous data will be summarised as Mean \pm SD (standard deviation) while discrete (categorical) in number and percentage. Quantitative data will be analysed by, mean, SD, t test. Quantitative data will be analysed by percentage, Chi square test, fisher exact test.

\section{RESULTS}

A total 50 patients were included in this study, male: female ratio was 4.6:1. Among the 50 patients, out of which 41 $(82.0 \%)$ were male, $18(36.0 \%)$ belonged to the 50 to 59 years age group, $15(30.0 \%)$ were having complaints for Ulcer, 15 (30.0\%) were smoker. The Amputation rate was $42.0 \%$ (Table 1)

Table No. 1: Socio demographic frequency classification of the patients with Diabetic foot Amputation or without Diabetic foot Amputation.

\begin{tabular}{|c|c|c|c|c|}
\hline Variables & \multicolumn{2}{|l|}{ Amputation } & \multirow[t]{2}{*}{ Total } & \multirow[t]{2}{*}{ P Value } \\
\hline Age Group & Yes & No & & \\
\hline $30-39$ & $1(25.0 \%)$ & $3(75.0 \%)$ & $4(100.0 \%)$ & \multirow[t]{6}{*}{$0.73 \mathrm{NS}$} \\
\hline $40-49$ & $3(25.0 \%)$ & $9(75.0 \%)$ & $12(100.0 \%)$ & \\
\hline $50-59$ & $9(50.0 \%)$ & $9(50.0 \%)$ & $18(100.0 \%)$ & \\
\hline $60-69$ & $5(50.0 \%)$ & $5(50.0 \%)$ & $10(100.0 \%)$ & \\
\hline $70-79$ & $2(50.0 \%)$ & $2(50.0 \%)$ & $2(100.0 \%)$ & \\
\hline$>=80$ & $1(50.0 \%)$ & $1(50.0 \%)$ & $2(100.0 \%)$ & \\
\hline \multicolumn{5}{|l|}{ Gender } \\
\hline Male & $20(48.78 \%)$ & $21(51.22 \%)$ & $41(100.0 \%)$ & \multirow[t]{2}{*}{0.038 Significant } \\
\hline Female & $1(11.11 \%)$ & $8(88.89 \%)$ & $9(100.0 \%)$ & \\
\hline \multicolumn{5}{|c|}{ Presenting complaints } \\
\hline Abscess & $2(25.0 \%)$ & $6(75.0 \%)$ & $8(100.0 \%)$ & \multirow[t]{7}{*}{$0.005 \mathrm{HS}$} \\
\hline Cellulities & $3(30.0 \%)$ & $7(70.0 \%)$ & $10(100.0 \%)$ & \\
\hline Gangrene & $10(83.33 \%)$ & $2(16.67 \%)$ & $12(100.0 \%)$ & \\
\hline Ulcer & $2(13.33 \%)$ & $13(86.67 \%)$ & $15(100.0 \%)$ & \\
\hline Necrotizing fasciitis & $2(66.67 \%)$ & $1(33.33 \%)$ & $3(100.0 \%)$ & \\
\hline Charcot's foot & $1(100.0 \%)$ & $0(00.0 \%)$ & $1(100.0 \%)$ & \\
\hline Osteomyelities & $1(100.0 \%)$ & $0(00.0 \%)$ & $1(100.0 \%)$ & \\
\hline \multicolumn{5}{|l|}{ Smoking } \\
\hline Yes & $7(46.67 \%)$ & $8(53.33 \%)$ & $15(100.0 \%)$ & \multirow[t]{2}{*}{$0.66 \mathrm{NS}$} \\
\hline No & $14(40.0 \%)$ & $21(60.0 \%)$ & $35(100.0 \%)$ & \\
\hline Total & $21(42.0 \%)$ & $29(58.0 \%)$ & $50(100.0 \%)$ & \\
\hline
\end{tabular}

Table No. 2: Clinical Examination in the study subjects.

\begin{tabular}{|c|c|c|c|c|}
\hline \multirow{2}{*}{ Variables } & \multicolumn{2}{|l|}{ Amputation } & \multirow[t]{2}{*}{ Total } & \multirow[t]{2}{*}{ P Value } \\
\hline & Yes & No & & \\
\hline \multicolumn{5}{|l|}{ PDA } \\
\hline Present & $4(44.44 \%)$ & $5(55.56 \%)$ & $9(100.0 \%)$ & \multirow[t]{2}{*}{$0.87 \mathrm{NS}$} \\
\hline Absent & $17(41.46 \%)$ & $24(58.54 \%)$ & $41(100.0 \%)$ & \\
\hline
\end{tabular}




\begin{tabular}{|l|l|l|l|l|}
\hline \multicolumn{5}{|c|}{ Table no 2 Continued... } \\
\cline { 1 - 4 } Wagner grading & \multicolumn{1}{|l|}{} \\
\hline Grade 0 & $0(00.0 \%)$ & $0(00.0 \%)$ & $0(00.0 \%)$ & \\
\cline { 1 - 4 } Grade 1 & $0(00.0 \%)$ & $0(00.0 \%)$ & $0(00.0 \%)$ & \\
\hline Grade 2 & $0(00.0 \%)$ & $12(100.0 \%)$ & $12(100.0 \%)$ & \\
\hline Grade 3 & $3(23.08 \%)$ & $10(76.92 \%)$ & $13(100.0 \%)$ & \\
\cline { 1 - 4 } Grade 4 & $14(70.0 \%)$ & $6(30.0 \%)$ & $20(100.0 \%)$ & \\
\cline { 1 - 4 } Grade 5 & $4(80.0 \%)$ & $1(20.0 \%)$ & $5(100.0 \%)$ & \\
\hline Total & $21(42.0 \%)$ & $29(58.0 \%)$ & $50(100.0 \%)$ & \\
\hline
\end{tabular}

In the above table no. 2 shows that the clinical examination about study subjects, among 50 patients, out of which 9 (18.0\%) were suffering from Peripheral artery disease \& 14 (66.7\%) were having grade 4 patients as per Wagner grading
In the below table no. 3 shows that the laboratory parameters according to the Diabetic foot amputation, among the 50 patients, $43(86.0 \%), 36(72.0 \%), 46$ $(92.0 \%) \& 17(34.0 \%)$ were found abnormal in TLC count, Albumin, HbA1C \& Bacteria culture respectively.

Table No. 3: Findings of the Laboratory parameters in with Diabetic foot Amputation \& without Diabetic foot Amputation patients.

\begin{tabular}{|l|l|l|l|l|}
\hline \multirow{2}{*}{ Variables } & Amputation & \multirow{2}{*}{ Total } & \multirow{2}{*}{ P Value } \\
\cline { 2 - 4 } & Yes & No & \\
\hline TLC & $1(14.29 \%)$ & $6(85.71 \%)$ & $7(100 \%)$ & \multirow{2}{*}{$0.11 \mathrm{NS}$} \\
\hline Abormal & $20(46.51 \%)$ & $23(53.49 \%)$ & $43(100 \%)$ & \\
\hline Albumin & $1(7.14 \%)$ & $13(92.86 \%)$ & $14(100 \%)$ & \multirow{2}{*}{$0.0018 \mathrm{HS}$} \\
\hline Normal & $20(55.56 \%)$ & $16(44.44 \%)$ & $36(100 \%)$ & \\
\hline Below Normal & $0(0 \%)$ & $4(100 \%)$ & $4(100 \%)$ & \\
\hline HbA1C & $21(45.65 \%)$ & $25(54.35 \%)$ & $46(100 \%)$ & \\
\hline Normal(4.6 - 6.4) & $20(60.61 \%)$ & $13(39.39 \%)$ & $33(100 \%)$ & 0.0002 HS \\
\hline Above Normal (>6.4) & \multicolumn{5}{|l|}{0} \\
\hline Bacteria culture & $1(5.88 \%)$ & $16(94.12 \%)$ & $17(100 \%)$ & \\
\hline Positive &
\end{tabular}

Table No. 4: Univariate analysis of Laboratory parameters with Diabetic foot Amputation \& without Amputation patients.

\begin{tabular}{|l|l|l|l|}
\hline \multirow{2}{*}{ Parameters } & Amputation & \multirow{2}{*}{ P Value } \\
\cline { 2 - 3 } & Yes & No & \\
\hline TLC & $22525.24 \pm 8195.28$ & $18091.03 \pm 7782.46$ & $0.058 \mathrm{NS}$ \\
\hline HbA1C & $8.47 \pm 1.41$ & $7.43 \pm 1.5$ & $0.0165 \mathrm{~S}$ \\
\hline Albumin & $2.24 \pm 0.58$ & $3.62 \pm 0.97$ & $0.123 \mathrm{NS}$ \\
\hline
\end{tabular}

In the above table no. 4 shows that amongst various laboratory investigations only $\mathrm{HbA1C}$ were statistically significant.

\section{DISCUSSION}

Diabetic mellitus is a major cause of non traumatic lower limb amputation. Various factors are responsible for amputations in patients of diabetic foot. This study was done in 50 patients who were admitted in Department of Surgery, Chalmeda Anand Rao Institute of Medical Sciences, Karimnagar, with different presentations of diabetic foot. They were followed during stay in the hospital.

In this study, majority of the patients were in 5 th \& 6th decades of life, $56.0 \%$ number of patients of age group between 50
- 59 years were $18(36.0 \%)$ patients \& between 60 - 69 years were 10 (20.0\%) which is comparable with previous study of Imad R Musa et.al. (5) in which the maximum number of patients were of age group between 50 - 59 years. Zameer Aziz et. al. (6) in a study of 100 patients with diabetic foot infection found majority to be amongst 5th and 6th decades of life was $59.0 \%$.

In this study gender classification, males were $82.0 \%$ \& females were $18.0 \%$, which is comparable with the previous study by Yufeng Jiang et. al. (7) which reveals $65.0 \%$ were males \& $30.04 \%$ were females and also with the study by $\mathrm{S}$ Morbach et.al. ${ }^{(8)}$ In which $58.7 \%$ of the patients were male, suggesting male preponderance. 
In our study total number of patients presenting with ulceration were $15(30.0 \%)$ out of which $13.33 \%$ underwent amputation. In the study done by Aziz Nather et.al. ${ }^{(6)}$ presentation of ulcer were $27.7 \%$. Followed by the study total number of patients presenting with gangrene were $24.0 \%$ out of which $83.33 \%$ underwent amputation. The rates of amputation were maximum among the patients presenting with features of gangrene. This was similar to the findings by Nawaf J. Shatnawi et. al. ${ }^{(9)}$ which had $31.0 \%$ patents with gangrene and also in the study by Aziz Nather et. al. (6) where gangrene was found in $31.7 \%$.

In this study total of 15 (30.0\%) had history of smoking out of which $46.67 \%$ underwent amputation. There were $70.0 \%$ patient without history of smoking out of which $40.0 \%$ underwent lower limb amputation. Also the relationship of smoking with lower limb amputation was found to be not a statistically significant, similar to the finding by Aziz Nather et. al. (6) where smoking was not found to be predictive factor for lower limb amputation.

Total of $9(18.0 \%)$ patients were found to be having suffering from peripheral arterial disease as compared to $41(82 \%)$ of those without having features of PAD. Among all of having features of PAD, 4 (44.44\%) underwent amputation as compared to $17(41.46 \%)$ who underwent amputation without having features of amputation. This was not comparable with the previous study by Andrej Brechow et al. (10)

Out of 50 patients, none of patients were grade 0 and 1, 12 (24\%) were of grade $2,13(26 \%)$ were of grade 3, $20(40 \%)$ were of grade 4 and $5(10 \%)$ were of grade 5 . Majority of the patients $33(66 \%)$ were of grade 3 and grade 4, this is in comparison with findings by Tjokorda Dde Dalem Pemayun et al. (11) where majority of patients, $75.5 \%$ were in grade 3 and grade 4 .

In my study 14 (28\%) patients had normal range of serum albumin out of which $1(7.1 \%)$ underwent amputation, $36(72 \%)$ patients had below normal level of serum albumin out of which 20 (55.56\%) underwent amputation. This is in concordance with the study of Nazri Mohd Yusof et al. ${ }^{(12)}$ and H.B Leung et al. ${ }^{(13)}$ who concluded low serum albumin to be an independent factor responsible for amputation.

Culture positivity was found in 33 $(66 \%)$ of samples out of which $20(60.61 \%)$ underwent amputation. Culture negative samples were $17(34 \%)$ out of which 1 (5.88\%) underwent amputation. This is in comparison with the previous study of Zameer Aziz et al. (6) who proposed bacterial culture positivity to be responsible factor for lower extremity amputation.

In my study 7 (14\%) patients had normal range of TLC out of which 1 (14.29\%) underwent amputation and 43 (86\%) patients had raised TLC out fo which $20(26.51 \%)$ underwent lower extremity amputation. This above finding was consistent with the findings of N. Saltoglu et al. ${ }^{(14)}$

In my study $4(8 \%)$ patients had normal range of $\mathrm{HbA1C}$ and none of them underwent lower limb amputation and 46 (92\%) had raised level of HbA1C out of which $21(45.65 \%)$ patients underwent lower line amputation. This is in concordance with the previous study Wenhui Zhao et al. ${ }^{(15)}$

\section{CONCLUSION}

In the results of analysis, poor glycemic control, peripheral arterial disease, peripheral neuropathy and higher Wagner grade are significant risk factors for amputation in diabetic foot infection. Strict control diabetes, which is the primary disease, is first of all required for the risk reduction.

Acknowledgement: None

Conflict of Interest: None

Source of Funding: None 
Ethical Approval: Approved by Institutional Ethical Committee

\section{REFERENCES}

1. IWGDF. Definition and criteria diabetic foot. 2015.

2. V.M, S.S, R.D, B.S, C.V. Epidemiology of type 2 diabetes: Indian scenario. Indian $\mathbf{J}$ Med Res [Internet]. 2007; 125(3):217-30.

3. World Health Organisation. Global report on Diabetes. Isbn [Internet]. 2016; 978:88.

4. Melton JG. Eighth Edition.2017.

5. Imad $\mathrm{R}$ Musa, Mohhanned O. N. A., Elsanousi I. S., Ibrahim F. A., Elsayed M. E. I., Gussay B. M., Rasha E. A., Tariq A., \& Gasim I. G. Factors associated with amputation among patients with diabetic foot ulcers in a Saudi Arabia. BMS Res Notes 2018; 11: 260. Doi: 10.1186/s13104018-3372-z.

6. Zameer Aziz., Wong K. L., Aziz Nather \& Chan Y. H. Predictive factors for lower extremity amputations in diabetic foot infections. Diabet Foot Ankle. 2012; 2. doi: 10.3402/dfa.v2i0.7463.

7. Yufeng J., Xingwu R., Lijing J., Chuan Y., Penghua W., Jianhua M., Bing C., Yanmei Y., Bo F., Lili C., Han Y., Zhifeng C., Zhaoli Y., Yuzhi Y., Fang 1., \& Zhangrong $X$. Epidemiology of Type 2 diabetic foot problems and predictive factors for amputation in China. Int $\mathrm{J}$ Low Extrem Wounds. 2015 Mar; 14 (1): 19 - 27. doi: 10.1177/1534734614564867.

8. S. Morbach., H. Furchert., Ute G., Heribert H., Kerstin K., Gerd-Thomas K., Ulrike K., Thomas R., Andrea I., Burkhard H., Gerhard R., Zulfiquarali G. A., Manish B., \& David G. A. Long term prognosis of diabetic foot patients and their limbs. Diabetes care. 2012 October; 35 (10): 2021 - 2027. https://doi.org/10.2337/dc12-0200.

9. Nawab J. S., Nabil A. A., Hassan M. H., Yousef S. K., Khaled G., \& Hussein A. H. Predictors of major lower limb amputation in type 2 diabetic patients referred for hospital care with diabetic foot syndrome.
Diabetes Metab Syndr Obes. 2018; 11: 313 319. doi: 10.2147/DMSO.S165967.

10. Andrej B., Torsten S., Dirk M., Thomas N., Hartmut P., Uta S., Stefan B., \& Matthias W. Improving major amputation rates in the multi complex diabetic foot patient: focus on the severity of peripheral arterial disease. There Adv Endocrinol Metab. 2013 Jun;4(3):83-94.

doi: $10.1177 / 2042018813489719$.

11. Tjokorda GDP., Ridho MN., Diana N., Nurmilawati A., \& Tania TM. Risk factors for lower extremity amputation in patients with diabetic foot ulcers: a hospital based case control study. Diabetic foot \& Ankle. 2015; $6 \quad 6 \quad$ (1): 29629. Doi:10.3402/dfa.v6.29629.

12. Yusof NM., Ab Rahman J., Zulkify AH., Che-Ahmad A., Khalid KA., \& Sulong AF. Predictors of major lower limb amputation among type II diabetic patients admitted for diabetic foot problems. Singapore Med J. 2015; 56(11): $626-31$.

13. HB Leung., YC Ho., WC Wong \& J Guerin. Seasonal variations in non traumatic major lower limb amputation in Hong Kong Chinese diabetic patients. Hong Kong Med J. 2007 Oct;13(5):379-81.

14. Saltoglu N, Yemisen M, Ergonul O, Kadanali A, Karagoz G \& Batirel A. Predictors for limb loss among patients with diabetic foot infections: An observational retrospective multi centre study in turkey Clin Microbiol infect. 2015; 21(7): 659 - 64.

15. Wenhui Z, Peter TK, Ronald H, Yujie W, Jolene J, Steven BH, William TC, Donna HR \& Gang Hu. HbAlc and lower extremity amputation risk in low income patients with diabetes. Diabetes care. 2013 Nov; 36(11): 3591-3598. doi: 10.2337/ dc13-0437

How to cite this article: Amara Simha Reddy. T, Prashant G.K. A study of the risk factors predicting Amputation in diabetic foot. Gal Int $J$ Health Sci Res. 2021; 6(3): 21-25. DOI: https://doi.org/10.52403/gijhsr.20210704 